\title{
ENRAIZAMENTO DE ESTACAS DE OLIVEIRA SUBMETIDAS A APLICAÇÃO DE FERTILIZANTES ORGÂNICOS E AIB
}

\author{
Rooting of olive tree cuttings using organic fertilizations and IBA
}

\author{
Marcelo Caetano de Oliveira ${ }^{1}$, João Viera Neto ${ }^{2}$, Rafael Pio ${ }^{3}$, \\ Adelson Francisco de Oliveira ${ }^{4}$, José Darlan Ramos ${ }^{1}$
}

\begin{abstract}
RESUMO
Estacas semilenhosas de oliveiras 'Ascolano 315', foram preparadas com aproximadamente $12 \mathrm{~cm}$ de comprimento e quatro folhas, sendo, em seguida, tratadas, ou não, com $3000 \mathrm{mg} \mathrm{L}^{-1}$ de AIB por cinco segundos O experimento foi conduzido em casa de vegetação, com sistema de nebulização intermitente, sendo as estacas colocadas em bancadas de propagação, contendo a perlita como substrato. Antes do plantio das estacas, foram aplicados os fertilizantes orgânicos Biofertilizante e Nippoterra, nas dosagens 0, 20, 40 e $60 \mathrm{~mL} \mathrm{~L}^{-1}$. Os produtos foram aplicados nas parcelas experimentais com regador manual, em dosagem única. Passados 58 dias, foi mensurada a porcentagem de estacas com calo, enraizadas, enraizadas e/ou com calo, número médio de raízes e comprimento médio das raízes. Concluiu-se que a dosagem de $40 \mathrm{~mL} \mathrm{~L}^{-1}$ de Biofertilizante propiciou melhores resultados, com a utilização de AIB.
\end{abstract}

Termos para indexação: Olea europaea L., olivicultura e propagação.

\section{ABSTRACT}

Semi hardwood cutting was colletecd in the medium portion of the 'Ascolano 315 ' olive trees, prepared with $12 \mathrm{~cm}$ in length and four leaves, treated or not with $3000 \mathrm{mg} \mathrm{L}^{-1}$ of IBA by five seconds. The experiment was conducted in a greenhouse, with a system of intermittent nebulization. The cutting was placed in propagation supports, containing perlite as a substrate. Before the plantation of the cutting, organic fertilizers Biofertilizante and Nippoterra were applied in the proportion: $0,20,40$ and $60 \mathrm{~mL} \mathrm{~L}^{-1}$. The products were applied in the experimental portions in a single dose. After 58 days, the percentage of cutting with callus, taken root, taken root and/or with callus, average number of roots and average length of the roots were evaluated. The $40 \mathrm{~mL} \mathrm{~L}^{-1}$ of Biofertilizante gave the best results, with IBA.

Index terms: Olea europaea L., oliviculture and propagation.

(Recebido em 9 de julho de 2008 e aprovado em 19 de março de 2009)

\section{INTRODUÇÃo}

A oliveira (Olea europaea L.) tem sido a base da agricultura dos países mediterrâneos, com grande importância econômica e social. Em Portugal, somente no Norte do país, na região de Trás-os-Montes, o cultivo de oliveiras cobre uma área de 70 mil ha, próximo a $6 \%$ do território (Figueiredo et al., 2002).

O grande interesse pelo consumo de azeitonas se deve as propriedades benéficas dos compostos encontrados nos frutos e mantidos durante o processamento, principalmente na fabricação do azeite. Os frutos da oliveira são ricos em polifenóis, como flavonóides, verbascoside e antocianina (Romani et al., 1999). Não só os frutos dessa planta milenar possuem propriedades nutriterapêuticas, sendo os extratos de folhas ricos em compostos fenólicos, principalmente flavonóides com capacidade antioxidantes (Benavente-García et al.,
2000). Por esses e outros motivos, quanto aos aspectos benéficos das oliveiras, o consumo de azeitonas e extratos é tão apreciado e requerido pela humanidade.

Apesar da oliveira ter sido introduzida no Brasil no início do século XX, principalmente em Minas Gerais, São Paulo e Rio Grande do Sul, foram instalados olivais sem bases técnicas, o que não permitiu maximizar o seu desenvolvimento. Nos últimos anos, a olivicultura passou a despertar interesse entre os produtores rurais no Sul de Minas Gerais, o que levou a Empresa de Pesquisa Agropecuária de Minas Gerais (Epamig) a intensificar os trabalhos de seleção varietal e manejo cultural dessa frutífera, principalmente quanto a produção de mudas de qualidade em escala comercial (Oliveira et al., 2006b; Oliveira et al., 2009).

O cultivo de oliveiras no Brasil é um fato real e recente, com novos plantios comerciais iniciados na região

1Universidade Federal de Lavras/UFLA - Departamento de Agricultura/DAG - Lavras, MG

${ }^{2}$ Empresa de Pesquisa Agropecuária de Minas Gerais/EPAMIG - Fazenda Experimental de Maria da Fé/FEMF - Maria da Fé, MG

3Universidade Federal de Lavras/UFLA - Departamento de Agricultura/DAG - Cx. P. 3037 - 37200-000 - Lavras, MG - rafaelpio@dag.ufla.br

${ }^{4}$ Empresa de Pesquisa Agropecuária de Minas Gerais/EPAMIG - Centro Tecnológico do Sul de Minas/CTSM - Lavras, MG 
Sul do Estado de Minas Gerais. O cultivo dessa frutífera, além de diminuir os gastos com importações, com $100 \%$ de todo o azeite consumido no Brasil, oriundos da Argentina, Portugal e Espanha, com importações anuais na ordem de 25 mil t, possibilitará também maior arrecadação de impostos diretos (Mesquita et al., 2006).

O método de multiplicação da oliveira adotado até o final do século XX, foi o enraizamento de estacas lenhosas de $60 \mathrm{~cm}$ de comprimento, alocadas diretamente na cova de plantio. No entanto, esse método apresenta inúmeras desvantagens, como o tamanho do propágulo, onerando o processo de multiplicação em larga escala, decorrente do gasto excessivo de material e ainda o fato da coleta das estacas serem realizada apenas uma vez ao ano. Atualmente, a multiplicação das oliveiras é realizada por meio de estacas semilenhosas de 12 centímetros de comprimento, dotadas de quatro folhas e enraizadas sob nebulização intermitente (Caballero \& Del Rio, 2006).

Uma das formas mais estudadas no favorecimento do balanço hormonal para o enraizamento é a aplicação exógena do fitoregulador AIB, por se tratar de uma substância fotoestável, de ação localizada e menos sensível à degradação biológica, em comparação às demais auxinas sintéticas, podendo, em muitas espécies de difícil enraizamento, viabilizar a produção de mudas por meio da estaquia (Hartmann et al., 2002Chagas et al., 2008; Bastos et al., 2009; Ohland et al., 2009 ). Na estaquia, muitas vezes, a aplicação de fitoreguladores é decisiva para a formação de raízes e tem por finalidade aumentar a porcentagem de estacas que formam raízes, acelerar sua iniciação, aumentar o número e a qualidade das raízes formadas e uniformizar o enraizamento (Fachinello et al., 2005).

Segundo Mancuso (1998), as estacas semilenhosas de oliveira possuem enraizamento na ordem de 20-30\%. Dependendo do cultivar, mesmo se aplicando AIB a base das estacas, não há incrementos expressáveis, conforme observado por Sebastiani \& Tognetti (2004), que constaram apenas $10 \%$ de enraizamento das estacas do cultivar Gentile di Larino.

O enraizamento de estacas semilenhosas, em canteiros com estrutura de nebulização intermitente e com mecanismos que permitem o aquecimento do substrato, instalados em casa de vegetação, possibilitou notáveis avanços no enraizamento de estacas de oliveira. Apesar de toda essa tecnologia, o percentual de enraizamento ainda é considerado baixo, a exemplo do trabalho desenvolvido por Oliveira et al. (2006a) que conseguiram apenas 30,3\% de enraizamento de estacas 'Ascolano 315', tratadas com $3000 \mathrm{mg} \mathrm{L}^{-1}$ de AIB em câmara de nebulização intermitente com sistema de aquecido de substrato.
Tem sido observado que a formação de raízes adventícias se deve à interação de fatores existentes nos tecidos e da translocação de substâncias sintetizadas nas folhas e gemas em desenvolvimento das estacas. Entre estes fatores, os fitohormônios e os nutrientes minerais são de fundamental importância (Henry et al., 1992).

Até o momento, não foram quantificados possíveis incrementos à rizogênese das estacas via aplicação de fertilizantes não salinos no substrato, durante o enraizamento. Como os nutrientes são essenciais a emissão das raízes nas estacas e alguns ainda participam como cofatores às auxinas, a exemplo do boro e zinco, os resultados com a fertilização suplementar ao substrato utilizado no enraizamento poderá aumentar os índices de enraizamento das estacas.

$\mathrm{Na}$ tentativa de se maximizar o potencial rizogênico de estacas semilenhosas de oliveira, realizou-se o presente trabalho com o objetivo de quantificar os índices rizogênicos de estacas de oliveira 'Ascolano 315' submetidas a aplicação de ácido indolbutírico (AIB) e diferentes doses de fertilizantes orgânicos durante o enraizamento.

\section{MATERIAL E MÉTODOS}

O presente trabalho foi realizado nas dependências da Fazenda Experimental de Maria da Fé (FEMF), da Epamig, Maria da Fé, MG. Estacas semilenhosas foram coletadas em novembro de 2007, na região mediana dos ramos em torno da copa, em plantas de oliveiras 'Ascolano 315', pertencentes ao banco de germoplasma da Epamig. As estacas foram padronizadas com, aproximadamente, 12 $\mathrm{cm}$ de comprimento e com quatro internódios, mantendo na região apical quatro folhas.

O experimento foi conduzido em casa de vegetação, com sistema de nebulização intermitente (automatizada por um temporizador regulado para acionar as $6 \mathrm{~h}$ e desligar as $22 \mathrm{~h}$, com nebulização acionada a cada cinco minutos por um período de 10 segundos), com temperatura controlada $\left(20 \pm 2^{\circ} \mathrm{C}\right)$, sendo as estacas plantadas em bancadas de propagação, a uma profundidade de quatro centímetros, utilizando como substrato a perlita.

Antes do plantio das estacas, foram aplicados os fertilizantes orgânicos comerciais Biofertilizante e Nippoterra, nas dosagens 20, 40 e $60 \mathrm{~mL} \mathrm{~L}^{-1}$, além da testemunha, composta somente com água sobre o substrato. Os produtos foram aplicados nas parcelas experimentais com regador manual, em dosagem única. Cada parcela apresentava uma dimensão de 1 x 0,16 x 0,2 m, com 32 litros de perlita, sendo regada com $2 \mathrm{~L}$ de solução. A porcentagem dos nutrientes contidos nos fertilizantes 
encontra-se na Tabela 1. Metade da base das estacas foram imersas por cinco segundos em solução hidroalcoolica de $3000 \mathrm{mg} \mathrm{L}^{-1}$ de AIB e a outra metade permaneceu sem aplicação do fitoregulador. Logo em seguida, as estacas foram enterradas a $2 / 3$ de seu comprimento no substrato.

Tabela 1 - Porcentagem de nutrientes em cada fertilizante orgânico utilizado nos referidos experimentos. Epamig, Maria da Fé, MG, 2008.

\begin{tabular}{ccc}
\hline Nutriente & \multicolumn{2}{c}{$\begin{array}{c}\text { Porcentagem de nutrientes em cada } \\
\text { fertilizante orgânico }\end{array}$} \\
\hline $\mathrm{N}$ & Biofertilizante & Nippoterra \\
$\mathrm{P}$ & - & 8,00 \\
$\mathrm{~K}$ & - & 6,00 \\
$\mathrm{Zn}$ & 0,10 & 15,00 \\
$\mathrm{Cu}$ & 0,34 & 0,20 \\
$\mathrm{Fe}$ & 0,02 & 0,05 \\
$\mathrm{Mn}$ & - & 0,20 \\
$\mathrm{~B}$ & 0,04 & 0,50 \\
$\mathrm{Co}$ & 0,18 & 0,40 \\
$\mathrm{Mo}$ & - & - \\
$\mathrm{S}$ & 0,43 & 0,05 \\
$\mathrm{Mg}$ & 0,12 & - \\
$\mathrm{Al}$ & - & - \\
$\mathrm{Si}$ & - & - \\
$\mathrm{Ca}$ & - & - \\
$\mathrm{Ti}$ & 0,64 & - \\
$\mathrm{C}$ orgânico & - & - \\
\hline
\end{tabular}

O trabalho foi dividido em dois experimentos, separadamente para cada fertilizante orgânico. O delineamento experimental utilizado foi o inteiramente casualizado, em esquema fatorial $2 \times 4$, sendo ausência ou aplicação de AIB (3000 mg L $\mathrm{m}^{-1}$ ) e o segundo fator as dosagens de cada fertilizante orgânico, com quatro repetições e cada parcela constituída por 25 estacas. Passados 58 dias, foi mensurada a porcentagem de estacas com calo, porcentagem de estacas enraizadas, porcentagem de estacas enraizadas e/ou com calo, número médio de raízes e comprimento médio das raízes. Os dados coletados foram analisados estatisticamente, utilizando o programa SISVAR (Ferreira, 2000). As porcentagens de estacas com calo, estacas enraizadas e estacas enraizadas e com calo, foram transformadas por arc sem $(\mathrm{x} / 100)^{1 / 2}$, com finalidade de proporcionar a normalidade dos erros.

\section{RESULTADOS E DISCUSSÃO}

Para o experimento envolvendo o fertilizante orgânico Biofertilizante, houve diferença estatística para porcentagem de estacas enraizadas, porcentagem de estacas enraizadas e/ou com calo e número médio de raízes quanto à utilização de AIB. Quanto ao emprego de diferentes dosagens do fertilizante orgânico Biofertilizante, observou-se diferenças estatísticas em todas as variáveis mensuradas, com exceção do comprimento médio das raízes. A interação entre esses dois fatores foi observada apenas para a porcentagem de estacas enraizadas.

Para o experimento envolvendo o fertilizante orgânico Nippoterra, foi verificada diferença estatística para as porcentagens de estacas enraizadas e porcentagem de estacas enraizadas e/ou com calo quanto a aplicação de AIB. Diferenças estatísticas quanto às dosagens do fertilizante orgânico Nippoterra foram verificadas para todas as variáveis a exceção do comprimento médio das raízes. Foi observada interação entre os fatores para a porcentagem de estacas enraizadas e porcentagem de estacas enraizadas e/ou com calo.

Quanto à aplicação de AIB em estaca da oliveira 'Ascolano 315', houve superioridade dos resultados com a aplicação exógena desse fitoregulador em todas as variáveis que vieram a apresentar diferença estatística (Tabelas 2 e 3). Esses resultados concordam com Oliveira et al. (2003) e Pio et al. (2005), que também verificaram incrementos significativos com a utilização de AIB, no potencial rizogênico de estacas semilenhosas de oliveira.

Para a porcentagem de estacas enraizadas, houve $6,09 \%$ de estacas enraizadas com o emprego de $40 \mathrm{~mL} \mathrm{~L}^{-1}$ do fertilizante orgânico Biofertilizante e sem o uso de AIB (Figura 1). Baixo enraizamento também foi observado com a utilização da dosagem de $60 \mathrm{~mL} \mathrm{~L}^{-1}$ do fertilizante orgânico Nippoterra sem AIB, obtendo-se apenas $11,3 \%$ de enraizamento, incremento 9,6\% em relação a testemunha (Figura 2). Por esses resultados, verifica-se que, apesar do enraizamento ser considerado baixo, há aumento do potencial rizogênico das estacas com o emprego dos fertilizantes orgânicos.

No entanto, com a utilização de AIB, à $3000 \mathrm{mg} \mathrm{L}^{-1}$, os resultados para a porcentagem de enraizamento obtidos foram de $61,24 \%$ de enraizamento com $40 \mathrm{~mL} \mathrm{~L}^{-1}$ do fertilizante orgânico Biofertilizante (Figura 1) e 50,3\% com $34 \mathrm{~mL} \mathrm{~L}^{-1}$ do fertilizante orgânico Nippoterra (Figura 2).

Para a porcentagem de estacas enraizadas e/ou com calo, registrou-se $58 \%$ com a aplicação do fertilizante orgânico Biofertilizante, com a dosagem de $60 \mathrm{~mL} \mathrm{~L}^{-1}$, incremento de 44,83\% em relação à testemunha(Figura $3 \mathrm{~A}$ ). Já, para o fertilizante orgânico Nippoterra, foi obtido $13,1 \%$ com a dosagem de $60 \mathrm{~mL} \mathrm{~L}^{-1}$ e sem AIB e 58,42\% com a dosagem de $32 \mathrm{~mL} \mathrm{~L}^{-1}$ e com AIB (Figura 3B). 
Tabela 2 - Porcentagem de estacas com calo (PEC), porcentagem de estacas enraizadas (PEE), porcentagem de estacas enraizadas e/ou com calo (PEEC), número médio de raízes (NMR) e comprimento médio das raízes (CMR, em centímetros) em estacas de oliveira 'Ascolano 315' com ou sem a aplicação de AIB no experimento com Biofertilizante. Epamig, Maria da Fé, MG, 2008.

\begin{tabular}{llllll}
\hline AIB & \multicolumn{5}{c}{ Variáveis analisadas* } \\
\cline { 2 - 6 } & PEC & PEE & PEEC & NMR & CMR (cm) \\
\hline Sem & $10,7^{\mathrm{ns}}$ & $3,7 \mathrm{~b}$ & $14,5 \mathrm{~b}$ & $0,9 \mathrm{~b}$ & $1,1^{\mathrm{ns}}$ \\
$3000 \mathrm{mg} \mathrm{L}^{-1}$ & 13,6 & $43,7 \mathrm{a}$ & $57,3 \mathrm{a}$ & $4,3 \mathrm{a}$ & 1,8 \\
C.V. $(\%)$ & 42,81 & 27,31 & 25,04 & 49,90 & 56,39
\end{tabular}

* Médias seguidas pela mesma letra na coluna não diferem significamente entre si, pelo teste de Tukey $(\mathrm{P} \leq 0,05)$. ns - não significativo, segundo o teste $\mathrm{F}$.

Tabela 3 - Porcentagem de estacas com calo (PEC), porcentagem de estacas enraizadas (PEE), porcentagem de estacas enraizadas e/ou com calo (PEEC), número médio de raízes (NMR) e comprimento médio das raízes (CMR, em centímetros) em estacas de oliveira 'Ascolano 315' com ou sem a aplicação de AIB no experimento com Nippoterra. Epamig, Maria da Fé, MG, 2008.

\begin{tabular}{llrrrl}
\hline AIB & \multicolumn{5}{c}{ Variáveis analisadas* } \\
\cline { 2 - 6 } & PEC & PEE & PEEC & NMR & CMR (cm) \\
\hline Sem & $1,7^{\mathrm{ns}}$ & $6,2 \mathrm{~b}$ & $8,0 \mathrm{~b}$ & $1,5^{\mathrm{ns}}$ & $1,3^{\mathrm{ns}}$ \\
$3000 \mathrm{mg} \mathrm{L}^{-1}$ & 3,7 & $24,5 \mathrm{a}$ & $28,3 \mathrm{a}$ & 2,4 & 1,5 \\
\hline C.V. $(\%)$ & 34,55 & 38,42 & 43,34 & 32,29 & 58,69 \\
\hline
\end{tabular}

* Médias seguidas pela mesma letra na coluna não diferem significamente entre si, pelo teste de Tukey $(\mathrm{P} \leq 0,05)$. ns - não significativo, segundo o teste F.

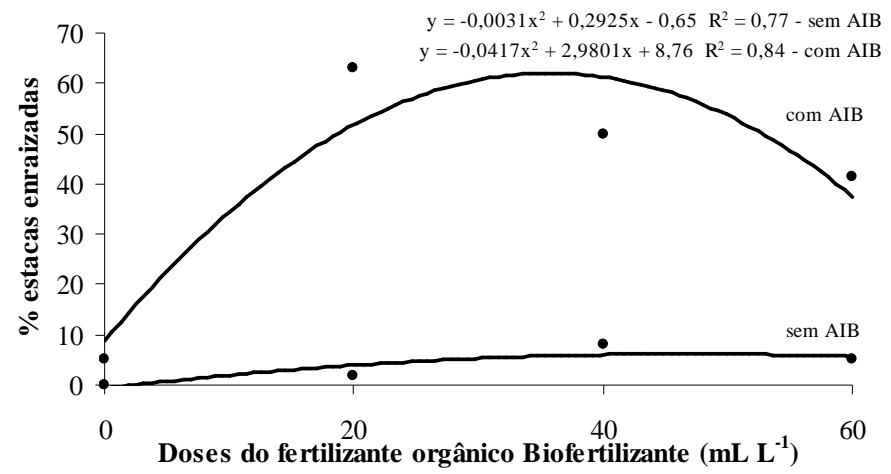

Figura 1 - Porcentagem de estaca enraizadas de oliveira 'Ascolano 315', tratadas ou não com AIB e submetidas a aplicação de diferentes dosagens do fertilizante orgânico Biofertilizante. Epamig, Maria da Fé, MG, 2008.

Segundo Oliveira et al. (2003), é possível o enraizamento de estacas semilenhosas de oliveira da 'Ascolano 315' utilizando-se instalações sem qualquer controle ambiental, podendo-se obter $29,85 \%$ de estacas enraizadas. Oliveira et al. (2006a), obtiveram 30,3\% de enraizamento em estacas da 'Ascolano 315', em câmara de nebulização com substrato aquecido (incremento de $0,45 \%$ ). No entanto, com a utilização de $40 \mathrm{~mL} \mathrm{~L}^{-1}$ do fertilizante orgânico Biofertilizante em estacas tratadas com AIB e adotando-se a utilização de câmara de nebulização intermitente sem aquecimento do substrato, há $31 \%$ de aumento nos índices de enraizamento, em relação aos trabalhos mencionados.

Os bons resultados obtidos para a porcentagem de enraizamento com a utilização dos fertilizantes orgânicos pode estar associada a presença de zinco (Zn) em ambos 
os fertilizantes (Tabela 1), elemento imprescindível para a melhoria da rizogênese em estacas, que em sinergismo ao AIB, proporcionou melhoria da rizogênese das estacas de oliveira.

O $\mathrm{Zn}$ é requerido na síntese do triptofano, um precursor do ácido indolacético, que é um fito-hormônio envolvido na formação de raízes adventícias (Blakesley et al., 1991).

O aminoácido é comum em plantas como constituinte de proteínas, e precursor intermediário da biossíntese de várias substâncias indólicas e ácido indolacético. É originário da rota do ácido shiquímico e forma auxinas endógenas via ácido indolpirúvico, triptamina, indolacetoaldoxima. A conversão via ácido indolpirúvico é feita por transaminação (Truelsen, 1973). Sendo citado também, que há possibilidade de transformação de L-triptofano em ácido indolacético via indolacetoaldoxima (Ludwig-Müller \& Hilgenberg, 1988). Tanto as formas "L" e "D" triptofano podem ser precursoras de ácido indolacético. Porém, o grande efeito da forma Dtriptofano induz a suposição de que este é o precursor mais direto.

Efeitos positivos com o emprego dos fertilizantes orgânicos foram constatados para a porcentagem de estacas calejadas, com 24,3\% com a utilização de $60 \mathrm{~mL} \mathrm{L-}$ ${ }^{1}$ do fertilizante orgânico Biofertilizante (Figura 4A). No entanto, para o fertilizante orgânico Nippoterra, obteve-se apenas 4,92\% com $30 \mathrm{~mL} \mathrm{~L}^{-1}$ (Figura 4B). Quanto ao número médio de raízes, dosagens entre 20 e $40 \mathrm{~mL} \mathrm{~L}^{-1}$ dos fertilizantes orgânicos propiciaram a emissão de três raízes por estaca (Figuras 5A e 5B).

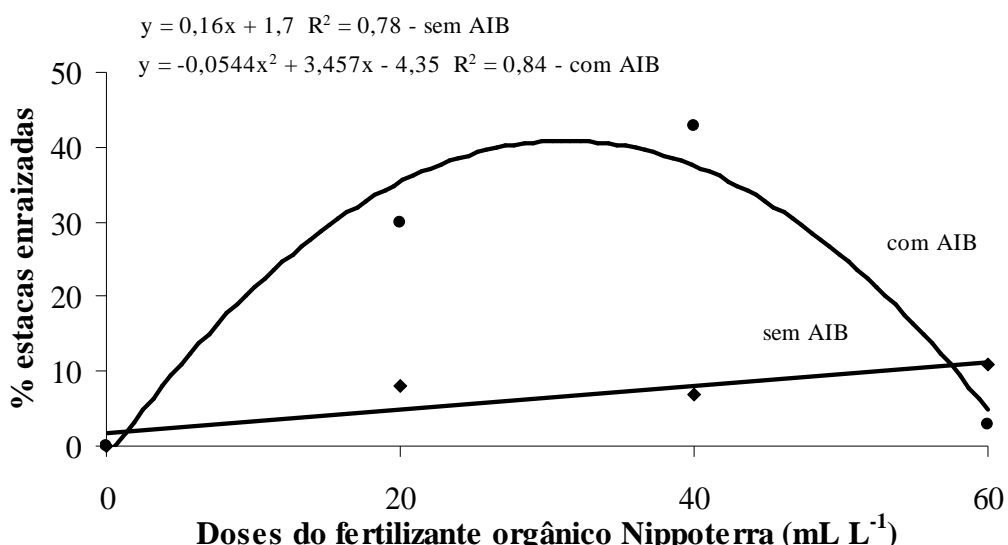

Figura 2 - Porcentagem de estaca enraizadas de oliveira 'Ascolano 315', tratadas ou não com AIB e submetidas a aplicação de diferentes dosagens do fertilizante orgânico Nippoterra. Epamig, Maria da Fé, MG, 2008.

A

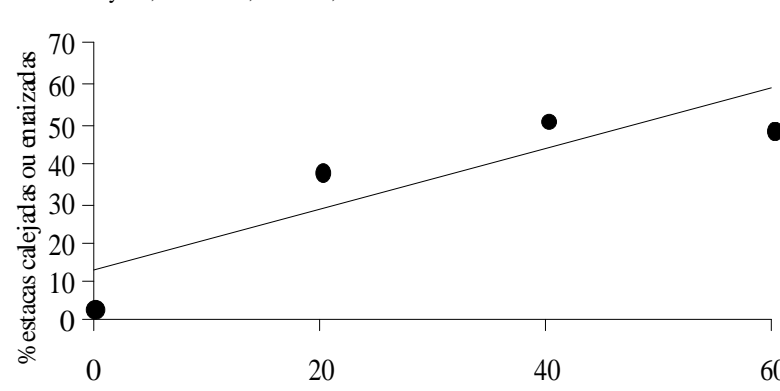

Doses do fetilizante orgânico Biofertilizante $\left(\mathrm{mLL}^{-1}\right)$
B

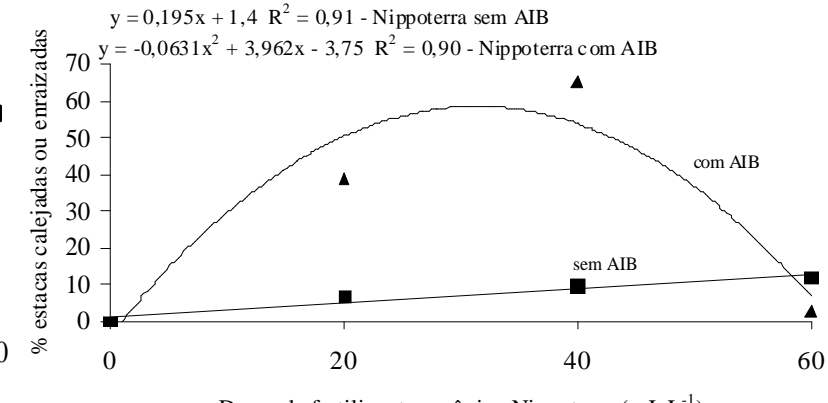

Doses do fertilizante orgânico Nippoterra $\left(\mathrm{mL} \mathrm{L}^{-1}\right)$

Figura 3 - Porcentagem de estaca calejadas ou enraizadas de oliveira 'Ascolano 315', tratadas ou não com AIB e submetidas à aplicação de diferentes dosagens dos fertilizantes orgânicos Biofertilizante (A) e Nippoterra (B). Epamig, Maria da Fé, MG, 2008. 
A

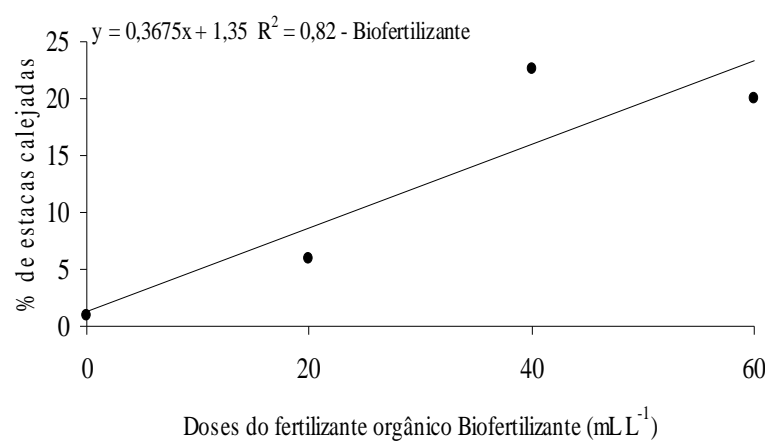

B

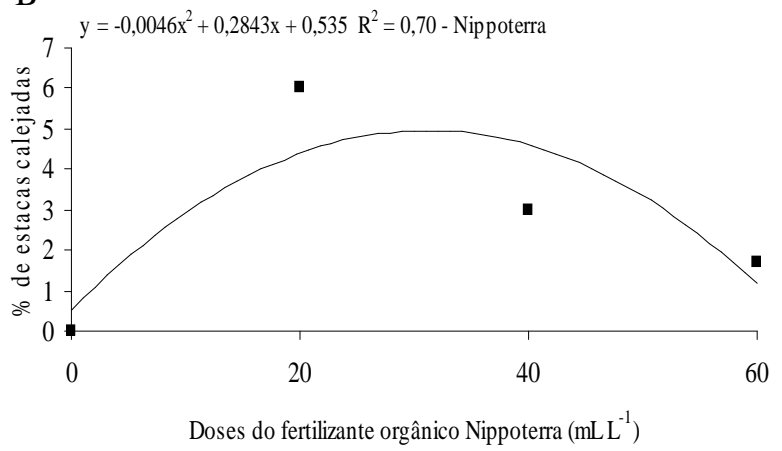

Figura 4 - Porcentagem de estaca calejadas de oliveira 'Ascolano 315' submetidas a aplicação de diferentes dosagens dos fertilizantes orgânicos Biofertilizante (A) e Nippoterra (B). Epamig, Maria da Fé, MG, 2008.
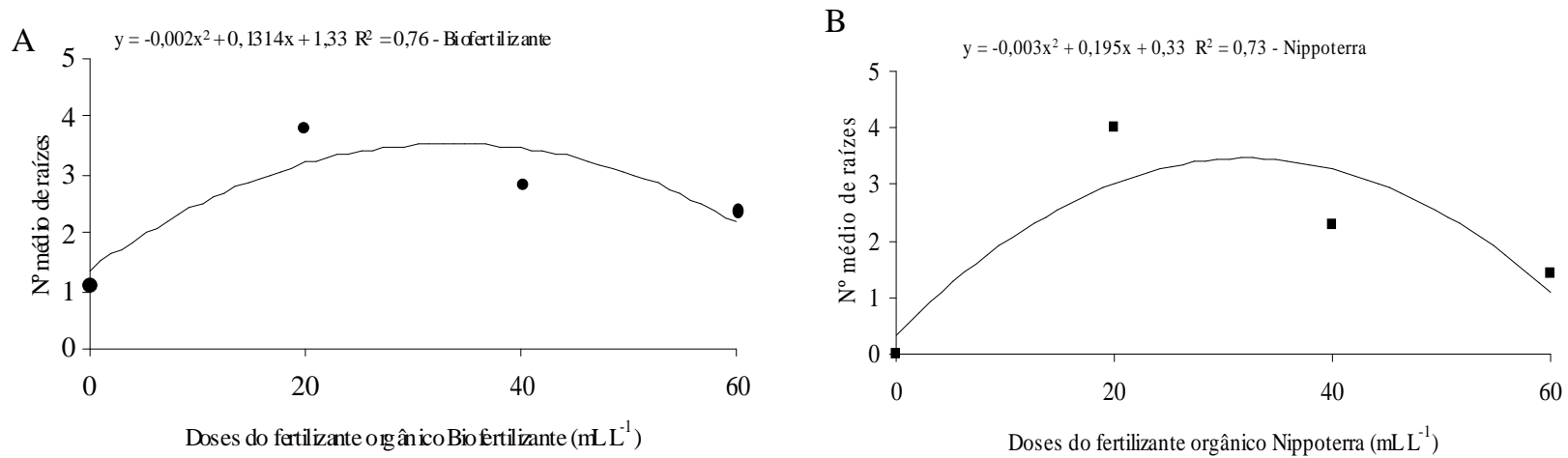

Figura 5 - Número médio de raízes em estacas de oliveira 'Ascolano 315' submetidas a aplicação de diferentes dosagens dos fertilizantes orgânicos Biofertilizante (A) e Nippoterra (B). Epamig, Maria da Fé, MG, 2008.

Em algumas variáveis mensuradas, verificaramse respostas quadráticas, ocorrendo saturação das respostas com incremento do fertilizante orgânico Nippoterra. Pela Tabela 1, verifica-se que esse fertilizante orgânico possui $8 \%$ de nitrogênio em sua constituição. Possivelmente, altas dosagens proporcionaram a acidificação do substrato. Assim, na escolha dos fertilizantes orgânicos, deve-se dar preferência para aqueles que não possuem nitrogênio em sua constituição.

No geral, a utilização do fertilizante orgânico Biofertilizante proporcionou melhores resultados em relação ao fertilizante orgânico Nippoterra. Segundo Wiesman \& Lavee (1995), as estacas de oliveira possuem dificuldade em emitir raízes e quando se adiciona sacarose ao meio de enraizamento, há incremento do potencial rizogênico. Pelo fato de o fertilizante orgânico Biofertilizante possuir carbono orgânico em sua composição (Tabela 1), pode ser um indício da superioridade dos resultados obtidos com a utilização desse fertilizante orgânico.

\section{CONCLUSÃO}

De acordo com os resultados obtidos, concluiu-se que:

- A utilização do AIB foi imprescindível na melhoria da rizogênese das estacas de oliveira;

- A aplicação de fertilizantes orgânicos ao leito de enraizamento, durante a estaquia da oliveira, aumenta o potencial rizogênico;

- Deve-se aplicar a dosagem de $40 \mathrm{~mL} \mathrm{~L}^{-1}$ do fertilizante orgânico Biofertilizante no leito de enraizamento.

\section{AGRADECIMENTOS}

Os autores deste artigo agradecem à Fundação de Amparo a Pesquisa do Estado de Minas Gerais - FAPEMIG, pelo apoio financeiro para a condução do projeto de pesquisa. 


\section{REFERÊNCIAS BIBLIOGRÁFICAS}

BASTOS, D. C.; FILHO, J. A. S.; LIBARDI, M. N.; PIO, R. Estiolamento, incisão na base da estaca e uso do ácido indolbutírico na propagação da caramboleira por estacas lenhosas. Ciência e Agrotecnologia, Lavras, v. 33, n. 1 p. 313 - 318, jan./fev., 2009.

BENAVENTE-GARCÍA, O.; CASTILLO, L.; LORENTE, J.; ORTUÑO, A.; DEL RIO, J.A. Antioxidant activity of phenolics extracted from Olea europaea L. leaves. Food Chemistry, London, v.68, n.4, p.457-462, 2000.

BLAKESLEY, D.; WESTON, G.D.; HALL, J.F. The role of endogenous auxin in root initiation. Plant Growth Regulation, v.10, p.341-353, 1991.

CABALLERO, J.M.; DEL RÍO, C. Propagação da Oliveira por enraizamento de estacas semilenhosas sob nebulização. Informe Agropecuário, Belo Horizonte, v.27, n.231, p.33-38, 2006.

CHAGAS, E. A.; PIO, R.; NETO, J. E. B.; SOBIERAJSKI, G. da R.; DALL'ORTO, F. A. C.; SIGNORINI, G. Enraizamento de estacas lenhosas de pessegueiro e clones de umezeiros submetidos à aplicação de AIB.

Ciência e Agrotecnologia, Lavras, v. 32, n. 3, p. 986 - 991, maio/jun., 2008.

FACHINELLO, J.C.; HOFFMANN, A.; NACHTIGAL, J.C. Propagação de plantas frutíferas. Brasília: Embrapa, 2005. 221p.

FERREIRA, D.F. Análise estatística por meio do SISVAR (Sistema para Análise de Variância) para Windows versão 4.0. In: REUNIÃO ANUAL DA REGIÃO BRASILEIRA DA SOCIEDADE INTERNACIONAL DE BIOMETRIA, 45., 2000, São Carlos. Anais... São Carlos: UFSCar, 2000. p.255-258.

FIGUEIREDO, T.; ALMEIDA, A.; ARAÚJO, J. Edaphic characteristics of olive-tree areas in the Trá-os-Montes region (Portugal): a map-based approach. Acta Horticulturae, The Hague, v.586, p.151-154, 2002.

HARTMANN, H.T.; KESTER, D.E.; DAVIES JUNIOR, F.T.; GENEVE, R.L. Plant propagation: principles and practices. 7.ed. New Jersey: Prentice Hall, 2002. 880p.

HENRY, P.A.; BLAZICH, F.A.; HINESLEY, L.E. Influence of stock fertility on adventicious rooting of stem cuttings. Journal of American Society

Horticultural Science, Alexandria, v.117, p.568-570, 1992.

LUDWIG-MULLER, J.; HILGENBERG, W. A plasma membrane-bound enzyme oxidizes L-tryptophan to indole- 3-acetaldoxime. Physiologia Plantarum, Copenhagen, v.74, p.240-250, 1988

MANCUSO, S. Seasonal dynamics of electrical impedance parameters in shoots and leaves relate to rooting ability of olive (Olea europaea) cuttings. Tree Physiology, Victoria, v.19, p.95-101, 1998.

MESQUITA, D.L.; OLIVEIRA, A.F.; MESQUITA, H.A. Aspectos econômicos da produção e comercialização do azeite de oliva e azeitona. Informe Agropecuário, Belo Horizonte, v.27, n.231, p.7-12, 2006.

OHLAND, T.; PIO, R.; CHAGAS, E. A.; BARBOSA, W.; KOTZ, T. E.; DANELUZ, S. Enraizamento de estacas apicais de figueira 'roxo de valinhos' em função de época de coleta e AIB. Ciência e Agrotecnologia, Lavras, v. 33, n. 1, p. 74 - 78, jan./fev., 2009.

OLIVEIRA, A.F.; ALVARENGA, A.A.; CHALFUN, N.N.J.; GONÇALVES, F.S. Enraizamento de estacas semilenhosas de oliveira em câmara úmida com aquecimento de substrato. Informe Agropecuário, Belo Horizonte, v.27, n.231, p.40-46, 2006 a.

OLIVEIRA, A.F.; ANTUNES, L.E.C.; SCHUCH, M.W. Caracterização morfológica de cultivares em coleção e considerações sobre o seu cultivo no Brasil. Informe Agropecuário, Belo Horizonte, v.27, n.231, p.55-62, 2006b.

OLIVEIRA, A. F. de; CHALFUN, N. N. J.; ALVARENGA, A. A.; NETO, J. V.; PIO, R.; OLIVEIRA, D. L. de. Estaquia de oliveira em diferentes épocas, substratos e doses de AIB diluído em $\mathrm{NaOH}$ e álcool. Ciência e Agrotecnologia, Lavras, v. 33, n. 1, p. 79-85, jan./fev., 2009.

OLIVEIRA, A.F.; PASQUAL, M.; CHALFUN, N.N.J.; REGINA, M.A.; RINCÓN, C.D.R. Enraizamento de estacas semilenhosas de oliveira sob efeito de diferentes épocas, substratos e concentrações de ácido indolbutírico. Ciência e Agrotecnologia, Lavras, v.27, n.1, p.117-125, 2003. 
PIO, R.; BASTOS, D.C.; BERTI, A.J.; SCARPARE FILHO, J.A.; MOURÃO FILHO, F.A.A.; ENTELMANN, F.A.; ALVES, A.S.R.; BETTIOL NETO, J.E. Enraizamento de diferentes tipos de estacas de oliveira (Olea europaea L.) utilizando-se ácido indolbutírico. Ciência e

Agrotecnologia, Lavras, v.29, n.3, p.562-567, 2005.

ROMANI, A.; MULINACCI, N.; PINELLI, P.; VINCIERI, F.F.; CIMATO, A. Polyphenolic Content in Five Tuscany Cultivars of Olea europaea L. Journal of Agricultural and Food Chemistry, Easton, v.47, n.3, p.964-967, 1999.

SEBASTIANI, L.; TOGNETTI, R. Growing season and hydrogen peroxide effects on root induction and development in Olea europaea L. (cvs. 'Frantoio' and 'Gentile di Larino') cuttings. Scientia Horticulturae, Amsterdam, v.100, p.75-82, 2004.

TRUELSEN, T.A. Indole-3-piruvic acid as an intermediate in the conversion of tryptophan to indole-3acetic acid: II., distribuition of tryptophan transaminase activity in plants. Physiologia Plantarum, Copenhagem, v.28, p.67-70, 1973.

WIESMAN, Z.; LAVEE, S. Relationship of carbohydrate sources and indole-3-butyric acid in olive cuttings. Australian Journal of Plant Physiology, Melbourne, v.22, n.5, p.811-816, 1995. 